\title{
Learners and learning contexts: international perspectives on new alignments for the digital age
}

\author{
Joke Voogt ${ }^{1}$ (D) Gerald Knezek ${ }^{2}$
}

Accepted: 11 March 2021 / Published online: 31 March 2021

(c) Association for Educational Communications and Technology 2021

\begin{abstract}
Twelve papers representing 59 authors from 16 different nations are included in this special issue addressing the theme of 'Learners and Learning Contexts: International Perspectives on New Alignments for the Digital Age'. Collectively, the papers represent a synthesis of international perspectives on next steps for bringing educational technology research findings into policy and practice that will benefit learners locally. Three meaningful clusters of topics have been identified among this collection of international collaborative works: (a) Learning and learning contexts, (b) Technology integration and teachers, and (c) Partnerships. Recommendations spanning the macro, meso and micro levels are addressed withing these papers, with an overall focus on learning.
\end{abstract}

Keywords Alignment - Learning · Learning contexts · Technology integration · Teachers · Partnerships · Digital age

\section{Introduction}

Educational researchers and policy makers have long known that research findings can take as long as one generation to become established in practice. The International Summit on ICT in Education (EDUSummIT) was founded in 2009 with the goal of fast tracking educational technology research findings from around the world into locally relevant policies and practices. EDUsummIT resulted from the scholarly work done for the International Handbook on Information Technology in Primary and Secondary Education (Voogt \& Knezek, 2008; Voogt et al., 2018). EDUsummIT is an invitational summit focusing on the integration of information and communication technology in education. The EDUsummIT community meets every two years and rotates between Europe, Asia and the Americas.

Joke Voogt

j.m.voogt@uva.nl

Gerald Knezek

gknezek@gmail.com

1 Department of Child Development and Education, University of Amsterdam, PO Box 15776, 1001NG Amsterdam, The Netherlands

2 Department of Learning Technologies, University of North Texas, UNT Discovery Park, 3940N. Elm St., Denton, TX 76207, USA 
The sixth EDUsummIT, was held in Laval University, Quebec City, Canada and had as its main theme 'Learners and Learning Contexts: New Alignments for the Digital Age'. Approximately 100-120 international key stakeholders participated in one of the thirteen Thematic Working Groups (TWGs). Each TWG focused on a specific subtheme. Participants were invited to discuss the TWG's subtheme from the perspective of research, policy and practice. Each TWG collected recent research evidence in an online preparation process before the three-day face-to face working meeting took place in October 2019.

In order to inform policy makers and practitioners about the EDUsummIT outcomes, an Action Agenda and an e-book have been published (Fisser \& Phillips, 2020). (https:// edusummit2019.fse.ulaval.ca/). The scholarly output of the EDUsummIT usually consists of a series of syntheses of research culminating in new conceptual models or frameworks, based on literature reviews and rich face to face dialog among leaders in the field. For this type of output, the Thematic Working Groups and all others in the world's scholarly community were invited to submit proposals to a special issue of ETRD related to the EDUsummIT theme, 'Learners and Learning Contexts: International Perspectives on New Alignments for the Digital Age'. Ten TWGs published their work in this special issue. In addition, two other papers were accepted that aligned with the theme of the Special Issue. All papers were subjected to a rigorous review process.

\section{Learners and learning contexts: international perspectives on new alignments in the digital age}

Research has shown that technology has the potential to offer new opportunities for enhancing teaching and learning, but the reality is that technology is often underused in educational practice (Cuban, 2001; Voogt \& Knezek, 2008; Voogt et al., 2018). Making use of the affordances of technology to foster learning assumes new interactions between technology, its users - teachers and learners-and contexts for learning (Cox \& Laferrière, 2020). However, current policies and daily routines at the macro, meso and micro level often inhibit the kind of interactions that are needed to realize the potential of technology for teaching and learning. The papers in this special issue identified three clusters where new alignments are needed in order to make technology work in the practice of education. These clusters are: (1) learning and learning contexts; (2) technology integration and teachers and (3) partnerships. Each contribution addresses a specific perspective on the theme of this special issue. The set of papers together offer an international perspective of research underpinning alignments that need to be in place in order for technology to foster student learning. The papers include recommendations for research, policy and practice.

\section{Cluster 1: learning and learning contexts}

The five papers in this cluster address two core questions: (1) What is worth learning in a digital society? and (2) What needs to be in place to foster learning in digital learning environments?

The first two contributions argue for the need to pay attention to the use of technology in fostering creativity and machine learning in the curriculum of compulsory education. Henriksen and colleagues reviewed the literature on creativity and technology in the curriculum and the implementation of this combination in classroom practice. Creativity and 
technology are both seen as important for education in the twenty-first century and the interaction between creativity and technology for education is considered promising (see for instance the special issue of The Creativity Journal, Glaveanu et al., 2020). However, creative uses of technology as well as technology that fosters creativity is not seen much in teaching and learning practices. The authors found in the literature four domains that dominate the discussion on creativity: (1) learning in regard to creativity; (2) the meaning of creativity; (3) discourses that surround creativity, and (4) futures on creativity and education. Each domain is contextualized based on the perspectives technologies may offer in fostering creativity. The authors conclude that agreed upon conceptualizations of creativity, technology and learning are needed to move forward in the implementation of creativity and technology for learning.

After their initial observation that machine learning is gaining ground in digital applications used in schools, Webb and colleagues elaborate on how machine learning affects human learners and learning. Webb and colleagues focus on deep learning as a subset of machine learning. They particularly examine the implications of the adaptive behavior of deep learning systems. They elaborate on the responsibility of humans for decisions regarding the design of such systems and the need to be able to explain and be accountable for the decisions taken. The authors argue that because of the impact of machine learning systems on humans it is important that every student has a basic understanding of the nature of machine learning systems and the social, legal, and ethical implications of these systems when they are used in education. For these reasons the authors advocate that machine learning becomes part of the compulsory curriculum in primary and secondary education. In their view students need to have opportunities to adapt and create machine learning systems in order to be able to act as responsible learners and citizens.

The plea of Webb and colleagues about the need for a basic understanding of machine learning is illustrated in the contribution by Ifenthaler and colleagues in this Special Issue about learning analytics. Learning analytics, in particular when they are embedded in digital systems, often are a specific form of machine learning. Ifenthaler and colleagues summarized the current literature on the conceptualization and the available empirical evidence regarding learning analytics. They conclude that for learning analytics to become practical in education, there is a need to better understand who owns the data and how the data are communicated to the persons (e.g. students, teachers, leadership and policy makers) who will use the learning analytics to make decisions about students' learning or teachers' functioning. The authors conducted a Delphi study in which experts agreed upon four essential conditions for sound and effective use of learning analytics in educational practice: (1) development of data literacy in all stakeholders; (2) updating of guiding principles and policies of educational data; (3) establishing standards for ethical practices with data quality assurance, and (4) flexible user-centered design for a variety of users of analytics. For each of these four areas strategies and actions are proposed.

Shonfeld and colleagues reflect on the cross-cultural implications of digital technologies in our networked society. Ideally, digital learning environment technologies offer ample opportunities for educational experiences where learners from different cultures are connected. In such cross-cultural projects leaners can develop important twenty-first century skills, such as digital skills, collaboration skills, inter-cultural skills and life long learning skills. However, such cross-cultural projects are not always easy to realize. Instead, the technologies needed to create the right digital environments often contribute to inequality, ethical issues and concerns about student well-being. From a social justice point of view the authors propose a cross-cultural alignment model to foster cross-cultural responsive teaching and learning. The model discusses the interactions and alignments that are needed 
between the educational system, digital environments, learners and educators for effective cross-cultural projects.

The final contribution within this cluster is about connected learning. Prestridge and colleagues describe the potential of connected learning environments facilitated by digital technologies. Core to connected learning is that it emphasizes self-driven actions and interactions for learning with a diversity of (digital) tools, people and ways of knowing. It offers opportunities for learning in formal and non-formal contexts and thus reframes learning in the digital age. The authors examine the complexities of connected learning by discussing three related concepts: (1) the open and bounded context of connected learning; (2) prescribed and emergent curriculum, and (3) the rise of a new class of influencer. Prestridge and colleagues envision connected learning as a new alignment for learning in the digital age.

\section{Cluster 2: technology integration and teachers}

Observations often show that the promises of technology for education and the use of technology in the actual practice of schools are often not aligned (Fraillon et al., 2020). The three papers in this cluster discuss this problem from different perspectives. Teachers are key in making the connection between promises and practices, but other factors, such as school leadership and infrastructure, plus curriculum and assessment requirements, also influence whether and how teachers use technology.

Factors that contribute to teachers' use of technology are described in technology integration models. The first paper elaborates on the function of such models in bridging theory with practice. Numerous conceptual models are available to guide the integration of technology in education. However criteria to judge the quality of the models are lacking. Building on quality criteria for scientific models, Tondeur and colleagues proposed and defined quality criteria for conceptual models, namely accuracy, consistency, scope, simplicity and fruitfulness. These criteria were applied to identify and discuss well-known technology integration models.

As teachers are designers and enactors of using technology for learning, the next two complementary contributions examine teachers' pedagogical reasoning and decision making about the integration of technology into classroom practice.

Forkosh-Baruch and colleagues identified barriers that affect pre- and in-service teachers pedagogical reasoning and offer opportunities to overcome these barriers. The authors propose an integrative model to identify the factors that affect pre- and in-service teachers pedagogical reasoning and decision-making. Also, in order to cope with the lack of authentic experiences pre-service teachers need to develop pedagogical reasoning and decisionmaking, the authors propose the use of teaching approximations, i.e. simulations of practice (role play, microteaching) that are less complex than real practice but offer opportunities for scaffolding pre-service teachers pedagogical reasoning. Such teaching approximations also need to be developed to foster teachers' responsible use of automated software systems that rely on algorithms. In addition such systems need to allow for teachers' autonomous use of the systems and the underlying algorithms used in the software need to be disclosed. This plea also relates to the call of Webb and colleagues, discussed above, that humans need to understand how machine learning works.

Stefianak and colleagues discuss pedagogical reasoning from the perspective of teachers as learning designers. They argue that pedagogical reasoning and decision-making is 
key in bridging the gap between instructional design and the real-world context of teaching and learning. From an understanding that designing for learning inherently implies dealing with uncertainty, Stefianak and colleagues developed a conceptual model to promote pedagogical reasoning and decision- making. They propose: (1) the use of external presentations (e.g., concept maps, prototypes, personas) as form of knowledge presentation; (2) reflection-in-action by prompting and internal dialogue during the design process; and (3) conjecturing strategies derived from experience with subject matter, design and the specific learning context.

\section{Cluster 3: partnerships}

The four papers in this section call for collaborative partnerships of the main stakeholders, specifically schools, universities and governments, to align intentions of technology use for teaching and learning with implementation in practice.

Tan and colleagues discuss seven domains where alignments are needed for successful use of the Knowledge Building Model and Knowledge Forum (Scardamalia \& Bereiter, 2014) to engage school aged students in knowledge creation. These domains are: (1) views of knowledge; (2) 21 st-century educational competencies; (3) education and equity; (4) pedagogy and technology integration; (5) assessment, learning and collaboration; (6) teacher learning; and (7) student learning outcomes. Tan and colleagues argue that alignments in each domain can only be realized through alliances between schools, universities and government.

The paper by Romero-Hall describes the diverse mix of initiatives of formal, non-formal, and informal networked learning opportunities in Latin America. However, barriers may prevent making full use of the opportunities of technologies for networked learning for every citizen in Latin America. Romero-Hall therefore recommends that policy makers and education leaders formulate long term strategic goals (including strategies for minimizing costs and maximizing opportunities for professional development), be sensitive to regional needs, and organize alliances between academia, governments and non-governmental and private organizations.

The contribution of Twining and colleagues discusses the curriculum renewing processes taking place because of the changes in the digital society. Many countries around the world are renewing their curriculum, as can be seen for instance in the OECD's project 'The future of Education and Skills - Education2030' (OECD, 2018). The authors examine the alignments needed to realize the intended outcomes of renewed curricula. Based on a sociocultural framework, alignments needed between policy and practice at the national and school level are conceptualized. The paper explores and exemplifies three issues that are key in realizing alignment: (1) stakeholder engagement; (2) teacher professionalism, and (3) summative assessment. The authors conclude that trust between policy and practice, and between the national and school level is a core attribute of alignment.

The last contribution under this cluster deals with sustainability and scalability of digital technology innovations. Howard and colleagues start from the assumption that dynamic and iterative processes are needed to make technological innovations sustainable and scalable. The authors present a model to visualize the dynamic relationship between organization, innovation, research and new contexts. Organization is at the core of the model and represents the need for collaboration between stakeholders, schools 
and research in particular, in order to realize sustainability and scalability for technology innovations. The utility of the model is illustrated in three cases from different parts of the world.

\section{Conclusion}

Collectively, the papers in this special issue represent a synthesis of international perspectives on next steps for bringing educational technology research findings into policy and practice that will benefit learners locally. Three clusters of topics have been identified, namely (a) Learning and learning contexts, (b) Technology integration and teachers, and (c) Partnership, within the overall theme of 'Learners and Learning Contexts: International Perspectives on New Alignments for the Digital Age'.

\section{Declarations}

Conflict of interest There are no potential conflicts of interest related to this publication.

Ethical approval This editorial introduction does not concern research on human and/or animal participants.

Informed consent Given the nature of this contribution informed consent informed consent is not required.

\section{References}

Cox, M., \& Laferrière, T. (2020). EDUsummIT 2019 - Learners and learning contexts: New alignments for the digital age. In P. Fisser, \& M. Phillips (Eds.), Learners and learning contexts: New alignments for the digital age: Report of EDUsummit 2019. (pp.4-7). https://edusummit2019.fse.ulaval. ca/files/edusummit2019_ebook.pdf

Cuban, L. (2001). Oversold and underused. Computers in the classroom. Harvard University Press.

Fisser, P., \& Phillips, M. (Eds.). (2020). Learners and learning contexts: New alignments for the digital age: Report of EDUsummit 2019. https://edusummit2019.fse.ulaval.ca/files/edusummit2019_ebook.pdf

Fraillon, J., Ainley, J., Schulz, W., Friedman, T., \& Duckworth, D. (2020). Preparing for life in a digital world. IEA International computer and information literacy study 2018 International report. Cham: Springer.

Glaveanu, V. P., Ness, I. J., \& de Saint Laurent, C. (2020). Creativity, learning and technology: Opportunities, challenges and new horizons. Creativity Research Journal, 32(1), 1-3. https://doi.org/10. $1080 / 10400419.2020 .1712167$

OECD. (2018). The future of education and skills: The future we want. Paris: OECDhttps://www.oecd. org/education/2030-project/

Scardamalia, N., \& Bereiter, C. (2014). Knowledge building and knowledge creation: Theory, pedagogy, and technology. In R. K. Sawyer (Ed.), The Cambridge handbook of the learning sciences (2nd ed., pp. 397-417). Cambridge University Press.

Voogt, J., \& Knezek, G. (Eds.). (2008). International handbook of information technology in primary and secondary education. Springer.

Voogt, J., Knezek, G., Christensen, R., \& Lai, K.-W. (Eds.). (2018). Second handbook of information technology in primary and secondary education. Springer international handbooks of education. Springer.

Publisher's Note Springer Nature remains neutral with regard to jurisdictional claims in published maps and institutional affiliations. 
Joke Voogt is Professor of ICT and Curriculum at the University of Amsterdam and Co-founder of EDUsummIT. Her research focuses on the integration of Information and Communication Technology in curriculum and educational practice in national and international settings.

Gerald Knezek is Regents Professor of Learning Technologies at the University of North Texas (UNT), USA, Co-director of the Institute for the Integration of Technology into Teaching and Learning (IITTL) and Co-founder of EDUsummIT. His teaching and research focuses on technology integration, measurement of socio-emotional constructs, STEM education and multidimensional scaling methods. 